\title{
THE DISTRIBUTION OF IMMUNE CELLS IN THE UVEAL TRACT OF THE NORMAL EYE
}

\author{
PAUL G. McMENAMIN \\ Perth, Western Australia
}

\begin{abstract}
SUMMARY
Inflammatory and immune-mediated diseases of the eye are not purely the consequence of infiltrating inflammatory cells but may be initiated or propagated by immune cells which are resident or trafficking through the normal eye. The uveal tract in particular is the major site of many such cells, including resident tissue macrophages, dendritic cells and mast cells. This review considers the distribution and location of these and other cells in the iris, ciliary body and choroid in the normal eye. The uveal tract contains rich networks of both resident macrophages and $\mathrm{MHC}$ class $\mathrm{II}^{+}$ dendritic cells. The latter appear strategically located to act as sentinels for capturing and sampling blood-borne and intraocular antigens. Large numbers of mast cells are present in the choroid of most species but are virtually absent from the anterior uvea in many laboratory animals; however, the human iris does contain mast cells. Small numbers of what are presumed to be trafficking lymphocytes are present in the uveal tract of normal eyes. There is little data available on the presence or absence of eosinophils. The role of these various cell types in immune homeostasis and ocular inflammation is briefly considered.
\end{abstract}

Local and systemic inflammatory and immunemediated disorders affecting the eye are propagated not only by newly infiltrating inflammatory cells but also by the complement of immune cells normally present in non-inflamed ocular tissues. In addition, immune cells in the normal eye almost certainly play an important role in local immunological homeostasis. Several types of immune cells, such as macrophages, dendritic cells, mast cells, lymphocytes and eosinophils, normally reside for various periods during their life cycle in peripheral tissues. The major aim of this review will be to consider the current state of knowledge on the distribution, phenotype and

Correspondence to: P. G. McMenamin, Department of Anatomy and Human Biology, The University of Western Australia, Nedlands (Perth) 6907 Western Australia. function of these cells in the normal iris, ciliary body and choroid. The role of such cell types in ocular inflammation, which will be discussed by other authors in this issue, is not the major focus of this review; however, a few issues will be briefly considered where appropriate.

\section{MACROPHAGES}

Mononuclear phagocytes arise from bone marrow precursors and after a brief journey in the blood as monocytes immigrate into tissues to become macrophages. In their mature form they are widely distributed throughout the body. Macrophages are professional phagocytes and play a pivotal role as effector cells in cell-mediated immunity and inflammation. ${ }^{1}$ In addition, due to their active secretion of a range of important biologically active molecules such as cytokines, reactive oxygen intermediates and nitric oxide, they play a role in other processes including immune regulation, tissue reorganisation and angiogenesis. ${ }^{1}$ The heterogeneous nature, function, morphology and immunophenotype of the monocyte/ macrophage series in different tissue microenvironments is well established. ${ }^{2}$ Cells recognised as belonging to the 'mononuclear-phagocyte system' include Kupffer cells (liver), mesangial cells (kidney), alveolar macrophages (lung), microglia (brain parenchyma and retina) and peritoneal macrophages. Macrophages undergo a complex process of activation driven by molecular inductive signals, e.g. interferon-gamma (IFN $\gamma$ ), usually at sites of inflammation. The activation process particularly involves 'young' or newly recruited macrophages (responsive macrophages). Resident tissue macrophages are poorly responsive to such signals. ${ }^{1}$ Fully activated macrophages are capable of effecting a range of destructive powers specifically targeted towards certain foreign organisms or tumour cells. An important, although less well understood aspect of macrophage biology is the nature of the signals responsible for suppressing activation. Activated 

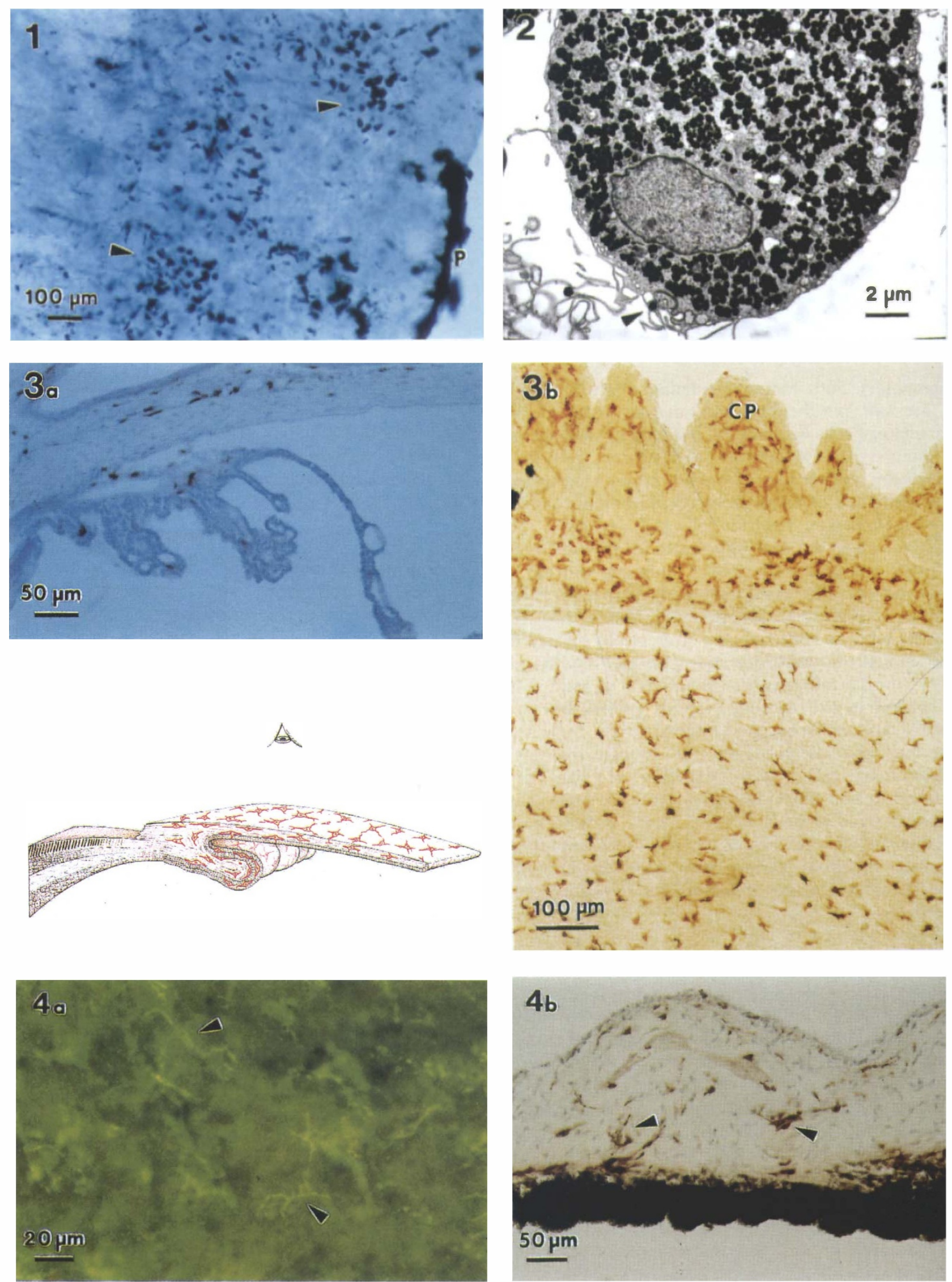
macrophages may express low/moderate amounts of major histocompatibility complex (MHC) class II molecule and thus may play a role in antigen presentation in secondary immune responses. ${ }^{3}$

\section{Macrophages in the Iris}

Classical histological and clinical studies described accumulations of large, heavily pigmented cells in the iris stroma close to the pupil margin, and near the iris base (Fig. 1), which were assumed to be of neuroepithelial origin. ${ }^{4}$ Electron microscopic studies ${ }^{5}$ revealed that there were two types of cells: type II clump cells, considered to display the morphological features of neuroepithelial cells, were rare; and type I cells, the predominant type, were considered to be melanin-containing macrophages (Fig. 2). More recently the use of specific anti-macrophage monoclonal antibodies (mAbs: ED1, ED2 and ED3) has revealed that the normal rat iris contains a rich network of resident tissue macrophages whose density and distribution is best appreciated in immunostained iris wholemount preparations (Fig. 3) ${ }^{6,7}$ Prior to the use of wholemounts there had been only a limited amount of data on the presence of macrophages in the iris stroma of the rat ${ }^{8}$ and mouse eye. ${ }^{9}$ Resident tissue macrophages in the normal iris display mixed morphological appearances ranging from pleiomorphic, bipolar to mildly dendriform (Fig. 3b) and are distributed in a largely perivascular and perineural manner similar to many other populations of resident interstitial macrophages. Quantitative studies in rodents ${ }^{6,7,10}$ indicate they are present at densities of $700-800$ cells $/ \mathrm{min}^{2}$. To the author's knowledge there are no studies of macrophages in human eyes using comparable investigative approaches. Immunostaining studies in humans are complicated by the presence of melanocytes; however, some preliminary immunofluorescence data (Fig. 4a) and conventional immunohistological studies (Fig. 4b) confirm the presence of a similar network of dendriform and pleiomorphic resident macrophages located throughout the iris stroma.

\section{Macrophages in the Ciliary Body}

Immunohistochemically stained wholemounts have revealed that macrophages are distributed in the connective tissue stroma of the ciliary body and ciliary processes in the rat and mouse eye (Fig. 3b). Laser scanning confocal microscopy, which provides 'optical sections' of the thick ciliary processes, is a valuable adjunct to conventional light microscopy in these studies. The relationship between macrophages and nerve fibres in dual immunofluorescent stained preparations is currently being investigated in our laboratory (Fig. 5a-c). Specific investigations of the distribution of macrophages in the normal human ciliary body are rare; however, studies by the author support the observations in rodents and suggest the human ciliary body is richly endowed with resident tissue macrophages (Fig. 6).

\section{Macrophages in the Choroid}

Like the anterior uveal tract the connective tissue stroma of the normal rodent choroid possesses a rich population of resident tissue macrophages. ${ }^{11,12}$ The choroid in the rat and mouse eye, which is only 20-30 $\mu \mathrm{m}$ thick in places (Fig. 7), can be processed for immunostaining as wholemounts either with the sclera attached (A. Kijlstra, personal communication) or as a separate layer dissected free from the sclera (Fig. 8). Such methods have revealed rich networks (approximately 600 cells $/ \mathrm{mm}^{2}$ ) of largely perivascular resident tissue macrophages throughout the choroid which are $\mathrm{ED}^{+}, \mathrm{ED} 2^{+}$and $\mathrm{ED}^{+}$in the rat $^{11,12}$ and SER4 ${ }^{+}$and $\mathrm{F} 4 / 80^{+}$in the mouse (Fig. 8).

The remarkably rich networks of resident tissue macrophages in the anterior and posterior uveal tract are likely to perform a variety of functions. In common with other populations of interstitial macrophages it is likely these cells are involved in phagocytosis of tissue debris, tumour cells and micro-organisms (see review ${ }^{13}$ ). The pattern of distribution of the resident tissue macrophages close to vascular beds suggests a sentinel or guardian role at the blood-tissue interface. Whether uveal tract macrophages possess $\mathrm{CD} 14$ and thus the

Fig. 1. Light micrograph of a human iris wholemount revealing the 'clump cells' (arrowheads) near the pupil margin (P). Note the posterior iris pigment epithelium has been brushed off.

Fig. 2. Transmission electron micrograph of a large melanin-containing macrophage characterised by large complex phagolysosomes, ruffled cell border and eccentric nucleus. A melanin granule in the process of being phagocytosed is identifiable (arrowhead).

Fig. 3. (a) Upper panel shows a frozen section of the rat anterior segment stained with ED2 mAb (anti-resident-tissue macrophages). Note that only rare cells can be identified in the iris and ciliary body using this method. The diagram in the lower panel illustrates the view of the iris and ciliary body obtained by preparing wholemounts. (b) Iris wholemount from a normal rat eye stained with ED2. Compare the numbers of cells in (b) with those in the upper panel in (a) CP, ciliary processes.

Fig. 4. (a) Immunofluorescence (PM2K, anti-human macrophage antibody) of human iris wholemount revealing pleiomorphic and dendriform immunopositive cells (arrowheads). (b) Conventional frozen section of the human iris stained with $P M 2 K$ and visualised with a red chromogen, to display the resident tissue macrophages in the stroma (arrowheads). 

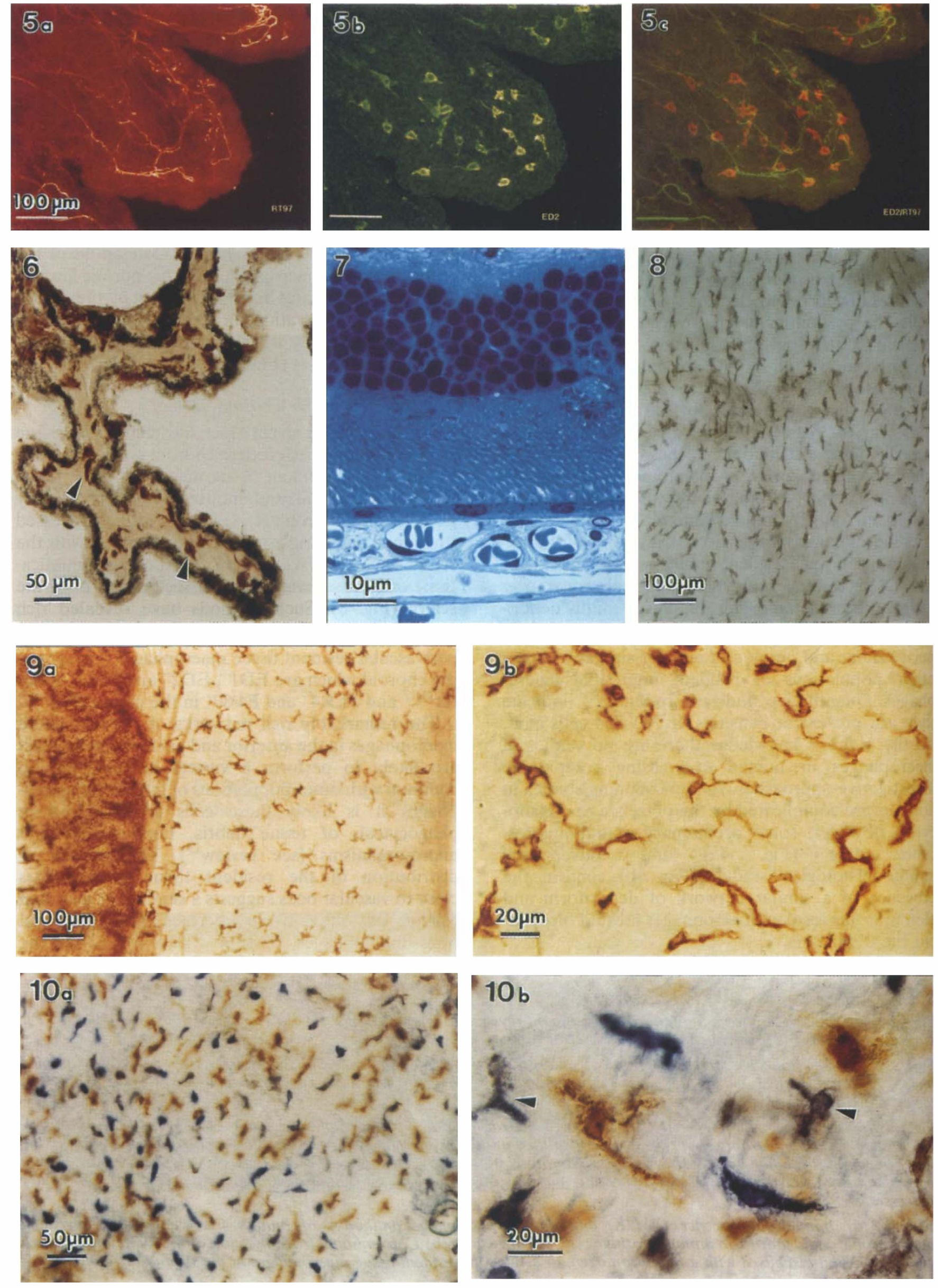
potential to bind LPS or LPS-binding protein is unknown. If this were the case these macrophages, via subsequent cytokine release, could rapidly initiate the inflammatory cascade in the eye. It is known that uveal tract macrophages produce proinflammatory substances such as nitric oxide (personal observation) and cytokines ${ }^{14}$ in conditions such as acute anterior uveitis or endogenous posterior uveitis. The possibility that uveal tract macrophages are $\mathrm{CD} 14^{+}$offers an attractive explanation for the particular susceptibility of the eye to exposure to systemic endotoxin (see reviews ${ }^{15,16}$ ).

Whilst uveal tract macrophages are relatively poor antigen presenting cells (APCs) in comparison with dendritic cells ${ }^{17}$ in primary immune responses, they may be efficient local APCs to primed T cells in secondary immune responses. This could be of particular importance in light of their close proximity to the blood-ocular barriers and fenestrated vascular beds of the choroid and ciliary processes. Interestingly, the pattern of distribution and density of resident macrophages does not appear to be particularly affected in the early stages of experimental autoimmune uveitis (EAU) and endotoxin-induced uveitis (EIU) and furthermore they quickly recover to normal density following the massive cellular infiltrate during the peak of disease in these models of uveitis. ${ }^{10,12}$

\section{DENDRITIC CELLS}

Members of the dendritic cell family play a pivotal role in the initiation of antigen-specific adaptive immune responses. ${ }^{18,19}$ Tissue-resident dendritic cells (DC) are characterised by their dendritic morphology, constitutive MHC class II expression and contiguous network arrangement. Whilst resident in peripheral tissue sites DC are specialised for antigen acquisition and processing and possess only a weak immunostimulatory capacity. ${ }^{20}$ DC are a dynamic population of weakly phagocytic immunoreactive cells whose turnover time seems to vary depending on the tissue, from 3 days in lymphoid organs to up to 7 weeks in skin. ${ }^{21}$ After a defined period of residence or following cytokine-mediated signals DC migrate via lymphatics or blood vessels (as 'veiled' cells) to the T-cell dependent areas of 'local' lymphoid tissues. Here they mature, under the influence of cytokines, particularly GM-CSF, ${ }^{22}$ into potent APC and present antigens/peptides within the groove of the MHC class II molecule on their cell surface to resting $\mathrm{T}$ cells. ${ }^{23}$ Secondary accessory signals, such as co-expression of B7 and adhesion molecules, are crucial for effective MHC class II/T cell receptor interactions and consequently $\mathrm{T}$ cell activation, tolerance and peripheral deletion or apoptosis. ${ }^{24}$ The specialisation of DC for antigen trapping, processing and presentation, along with their migratory properties, has led to them being regarded as the 'sentinels' of the immune system. ${ }^{18}$ In addition, they are many times more potent at initiating and perpetuating secondary immune responses than other APC such as B cells and macrophages. DC have attracted considerable attention as important 'passenger cells' in transplants able to sensitise host $\mathrm{T}$ cells against graft antigens and initiate graft rejection.

\section{Dendritic Cells in the Iris}

Following the discovery that MHC class II expression was important to the outcome of transplantation and in the aetiology and pathogenesis of autoimmune disease many groups investigated the pattern of expression of this molecule in normal and diseased ocular tissues. Most of these studies, performed on conventionally sectioned tissue, either failed to reveal any MHC class $\mathrm{II}^{+}$cells or revealed only occasional, scattered cells in the normal eye. . $^{26}$ More recently the combined use of immunohistochemistry and wholemount methods demonstrated a contiguous network of MHC class DC in the iris (Fig. 9). ${ }^{6,7,27}$ In all species examined iris DC display a variety of forms from pleiomorphic to the characteristic highly dendriform morphology with multiple, often branched cytoplasmic processes and an indented nucleus. The cells do not display such a strong orientation along blood vessel walls as resident tissue macrophages (Fig. 9a). The density of iris DC in rodents $\left(400-500\right.$ cells $\left./ \mathrm{mm}^{2}\right)$ is slightly less than in tissue macrophages. Double colour immunohistochemical studies ${ }^{7}$ (Fig. 10a,b) have revealed that DC do not co-localise with anti-

Fig. 5. Confocal microscopic images (Z-series) of a normal rat ciliary process stained for (a) neurofilaments (RT 97 , red) and (b) resident tissue macrophages (ED2, green) The two images are combined in (c) but the colours have been reversed. Fig. 6. Light micrograph of human ciliary process immunostained to reveal resident tissue macrophages $\left(P M 2 K^{+}\right)$in the connective tissue stroma (arrowheads).

Fig. 7. Semithin resin section $(1 \mu \mathrm{m})$ of the rat outer retina and choroid to demonstrate the thickness of the choroid removed during wholemount preparations.

Fig. 8. Mouse choroidal wholemount stained with an anti-resident-tissue macrophage antibody (SER4).

Fig. 9. (a) Low-power view of mouse iris-ciliary body wholemount stained with anti-MHC class II antibodies (M5/114) to reveal the network of dendritic cells $(D C)$. (b) High-power view of a few DC.

Fig. 10. Low-power (a) and high-power (b) views of double colour immunohistochemical stained rat iris wholemount preparation. Macrophages are ED2 $2^{+}$(blue chromogen) and DC are MHC class $I^{+}(O x 6$, red chromogen). Note that the two populati ns are distinct and only a few purple cells indicate co-localisation of both markers. 

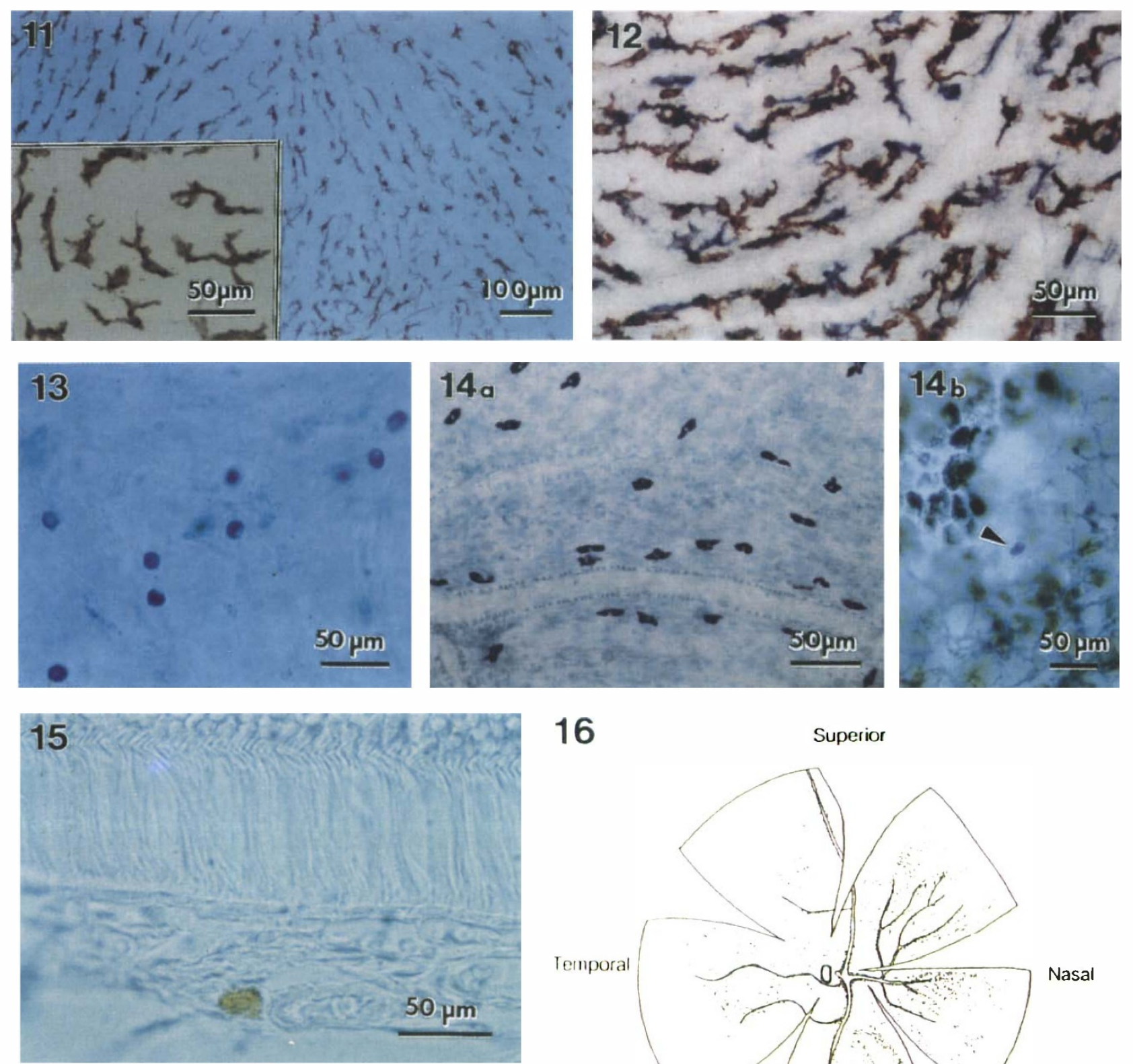

16 Superior

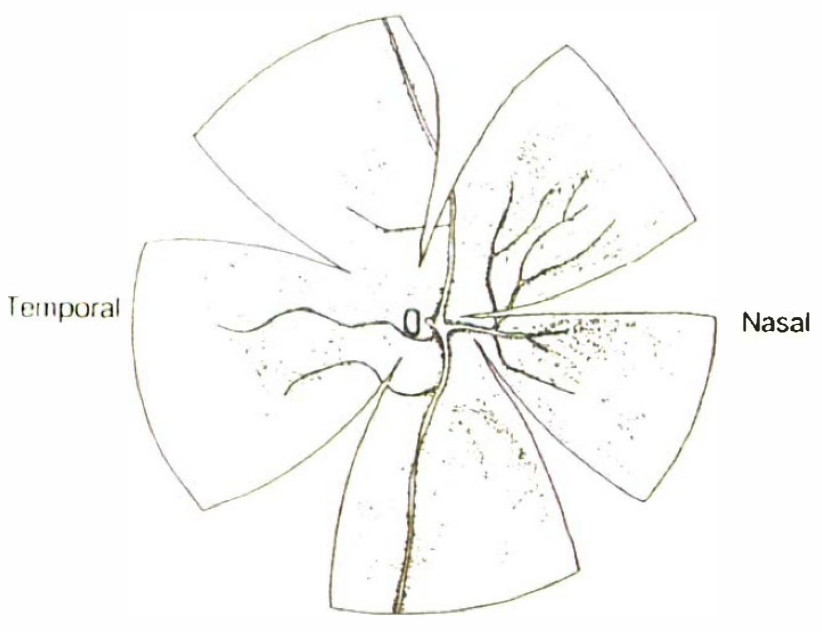

Inferior
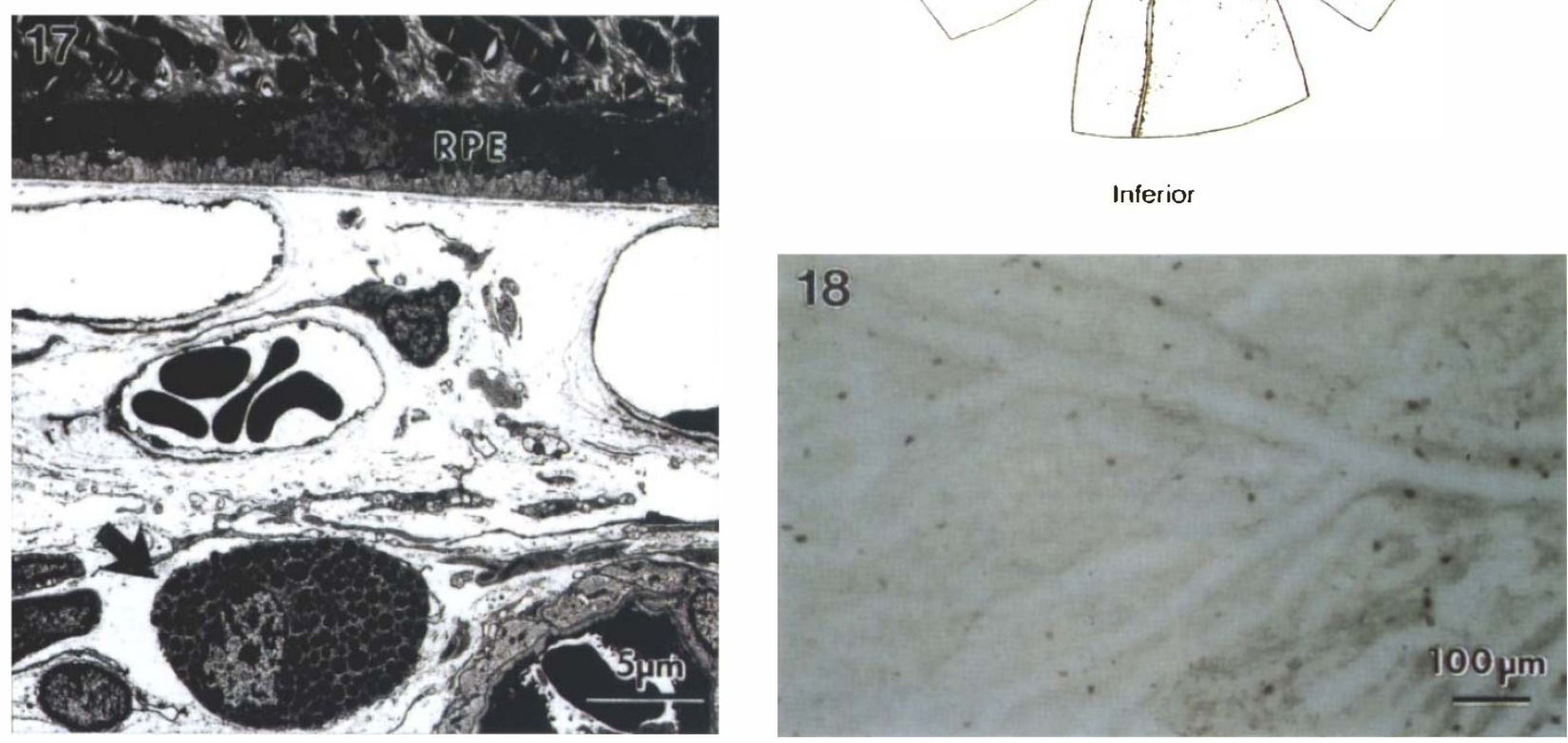
macrophage monoclonal antibodies. This phenotypic characteristic is important in the classification of DC. ${ }^{18}$

Recently our group has shown that purified iris DC have the functional capacity to stimulate naive $\mathrm{T}$ cells in a mixed lymphocyte response (MLR) similar to conventional DC, such as epidermal Langerhans cells (LC) ${ }^{17}$ Iris DC, like other 'immature' DC in peripheral tissues which are weak APC, require appropriate cytokine maturational signals such as GM-CSF in order to display potent stimulatory capacity in an MLR assay. ${ }^{17}$ The last piece of conclusive evidence that was required to establish that $\mathrm{MHC}$ class $\mathrm{II}^{+}$cells in the iris are equivalent to DC in other non-lymphoid tissue sites was the question of their migratory capacity. DC from all non-lymphoid tissue sites thus far studied regularly traffic to local lymphoid tissues where they present peptides from antigens encountered whilst resident in peripheral tissues. ${ }^{28}$ The issue of iris DC migration has recently been addressed in our laboratory. ${ }^{29}$ We have shown, using $\mathrm{X}$-irradiation bone marrow ablation, that iris DC have a half-life of 2-3 days in comparison with 10 days for skin LC in the same experiments and approximately 10 days for ED2 ${ }^{+}$iris macrophages. This rapid turnover of iris DC is comparable to that in DC populations in mucosal surfaces such as the respiratory ${ }^{30}$ and gastrointestinal tracts. ${ }^{31}$ Until recently it was assumed that due to the absence of lymphatics in the eye antigenic signals, presumably cell-associated, leave the anterior chamber and traffic to the spleen. $^{32}$ However, there is exciting new experimental evidence ${ }^{33}$ that antigens from the anterior chamber reach submandibular lymph nodes. Whether iris DC are the cells responsible for transmitting these signals has yet to be determined, but it would seem highly likely.

\section{Dendritic Cells in the Ciliary Body}

A rich network of MHC class $\mathrm{II}^{+} \mathrm{DC}$ is present in the ciliary body stroma and interposed between the two layers of the ciliary epithelium of the ciliary processes on the vascular side of the blood-aqueous barrier. ${ }^{7}$ At this latter site they are ideally situated to sample antigens arriving via the fenestrated vascular bed and/or those present in the posterior chamber and vitreous. There are no functional studies or migration data specifically pertaining to these cells due to the difficulty in isolating pure populations from such small pieces of tissue in rodent eyes.

\section{Dendritic Cells in the Choroid}

It has only recently become apparent that the rat choroid, like the anterior uveal tract, contains a rich population of DC. ${ }^{11}$ Earlier studies slightly underestimated the densities of these cells in the rat choroid (373 cells $\left./ \mathrm{mm}^{2}\right) ;{ }^{11}$ however, more recent studies, in which fixation and wholemount techniques have been modified, demonstrated $746 \pm 37$ cells/ $\mathrm{mm}^{2}$ in the normal rat choroid. ${ }^{12}$ Subsequent investigations have confirmed that cells of the DC phenotype are present in similar densities in the mouse choroid (Fig. 11) (personal observation). In common with the iris, choroidal DC form a network distinct from choroidal macrophages (Fig. 12). Immunoelectron microscopic studies have shown that DC have fine processes directly adjacent to the basal aspect of the retinal pigment epithelial cells and Bruch's membrane, ${ }^{11}$ namely where they are in an ideal position to sample retinal proteins. There are to date no immunohistochemical studies of DC in the normal human choroid. Functional studies of rat DC isolated from preparations of the entire posterior segment (retina, choroid and sclera) suggest they are similar to iris DC as assessed by mitogenesis assays and allostimulatory capacity in MLR assays. ${ }^{34}$ There are no data available on turnover of choroidal DC; however, observations in our laboratory using rat

Fig. 11. Mouse choroidal wholemount stained with anti-MHC class $I I^{+}$monoclonal antibody (M5/114) to reveal the network of DC. Inset: high-power view of a few DC.

Fig. 12. Double colour immunostained choroidal wholemount showing $M H C$ class $I I^{+} D C$ (red) and ED2 $2^{+}$macrophages (blue).

Fig. 13. Human iris wholemount stained with toluidine blue examined by conventional light microscopy. The iris pigment epithelium has been brushed off the posterior surface to aid light transmission.

Fig. 14. Rat (Lewis) (a) and human (b) choroidal wholemount stained with toluidine blue to reveal mast cells [arrowhead in (b)]. In (b) note the dendriform choroidal melanocytes and ovoid retinal pigment epithelial cells.

Fig. 15. RMCPI mast cell (connective tissue phenotype) in a histological preparation of the rat choroid and retina. Note the periarteriolar location of the mast cell in the outer choroid.

Fig. 16. Camera lucida drawing of the rat choroid to display the distribution of mast cells in a wholemount preparation. Each dot represents a single mast cell. The large vessels are the long posterior ciliary arteries.

Fig. 17. Transmission electron micrograph of the normal rat choroid containing a mast cell (arrow). Note the periarteriolar location of the mast cell in the outer choroid (compare with Fig. 15).

Fig. 18. Rat choroid wholemount stained with anti-CD8 antibody. Note the occasional cell distributed throughout the choroid. 
chimaeras suggest they are replenished by bonemarrow-derived precursors.

\section{MAST CELLS}

Besides their well-known role in IgE-mediated hypersensitivity responses, mast cells have been implicated in a range of non-IgE-mediated immunological and pathological processes including responses to parasites and neoplasms, chronic inflammation, fibrosis, angiogenesis and wound healing. ${ }^{35,36}$ In addition to pre-formed stored mediators (e.g. histamine, heparin) mast cells are known to be a potent source of many de novo synthesised proinflammatory cytokines and chemokines. ${ }^{36}$ They also appear to regulate blood flow in some tissues and organs. ${ }^{37}$

\section{Mast Cells in the Iris}

There have been a number of studies of the distribution of mast cells in the normal irides of various species (Table I) ${ }^{38-44}$ They are absent or extremely rare in rabbits, rats and mice, but are present in some carnivores (e.g. dogs, cats), marsupials and humans, although no true estimates of density are available in the literature. In the human iris they appear more randomly distributed than in the choroid where they are periarteriolar (see below).

Mast cells are best studied by histochemical staining of wholemounts, a fact utilised in the earliest studies of these cells. ${ }^{39}$ However, in pigmented eyes the quantity of iris melanin makes visualisation difficult, although the iris pigment epithelium can be removed from the posterior surface to aid light transmission through specimens (Fig. 13). Mast cells, due to their low density, are seldom encountered in transmission electron microscopic studies in the iris. The few ultrastructural images available ${ }^{45}$ suggest that human mast cells are of the connective tissue phenotype. No immunohistochemical studies of mast cells in the human iris have been performed to confirm this suggestion.

\section{Mast Cells in the Ciliary Body}

The distribution of mast cells in the ciliary body is similar to that described for iris. They are absent or rare in rodent eyes: 0.3 per eye (Brown Norway rat) to 69 per eye (Lewis rat). ${ }^{46,47}$ When present they are distributed in the connective tissue stroma of the

Table I. Mast cells in the iris (previous literature)

\begin{tabular}{ll}
\hline Taxon & Frequency \\
\hline Rodentia (mouse, rat) & Rare/absent $^{38,39}$ \\
Caviidae (guinea pigs) & Rare/absent $^{38,39}$ \\
Lagomorpha (rabbits) & Absent $^{40}$ \\
Carnivores (cats, dogs) & Common $^{41}$ (130 per section) \\
Marsupials & Present $^{42}$ \\
Primates (humans) & Present $^{43,44}$ \\
\hline
\end{tabular}

ciliary body and ciliary processes, a pattern also found in humans where they are interspersed among the muscle fibres. They have also been noted during early development in the ciliary body of marsupial eyes. $^{42}$

\section{Mast Cells in the Choroid}

The distribution of mast cells in the choroid has been more intensively investigated in comparison to the iris and ciliary body (see review ${ }^{38}$ ). This interest was partly motivated by the hypothesis that the density of choroidal mast cells in various rat strains was correlated with their susceptibility to EAU induction. ${ }^{48}$ Within the choroid, mast cells have a characteristic periarteriolar distribution (Figs. 14a, $15,16)$, primarily along the long posterior ciliary arteries (LPCA) and their branches (Fig. 16). In most other tissue sites mast cells display a perivenular location, except in the meninges where they are also periarteriolar. ${ }^{49}$ Histochemical and immunohistochemical studies have revealed rat choroidal mast cells are of the connective tissue phenotype, containing mixed alcian blue/safranin ${ }^{+}$granules (not illustrated) and Rat Mast Cell Protease $\mathrm{I}^{+}$granules (Fig. 15) ${ }^{50}$ This protease is considered a definitive marker for rat connective tissue mast cells. Transmission electron microscopy confirms these findings by revealing rat choroidal mast cell granules to be of uniform diameter (Fig. 17). Rat mucosal mast cells have granules more heterogeneous in size. ${ }^{51}$ Although mast cells are present in the human choroid $^{38}$ (Fig. 14b) their precise phenotype and density are unknown.

As mentioned above, early investigations described high densities of mast cells in rat strains susceptible to the induction of EAU (e.g. Lewis, 50 cells $/ \mathrm{mm}^{2}$ ) and low densities in resistant strains (Brown Norway, 0.2 cells $/ \mathrm{mm}^{2}$ ). Furthermore, choroidal mast cell degranulation was reported to occur around 7-8 days after immunisation with retinal antigens ${ }^{52}$ and therefore postulated to be an initiating event in the cellular infiltration. ${ }^{52}$ Subsequent studies in our laboratory ${ }^{50,53}$ failed to support this theory since very low densities $\left(1.9\right.$ cells $\left./ \mathrm{mm}^{2}\right)$ were found in mildly susceptible rat strains such as PVG and studies of mast cells in EAU revealed a peak in degranulation accompanying disease onset (days $12-14) .^{53}$

\section{LYMPHOCYTES}

Lymphocytes comprise two basic functional subsets: $\mathrm{T}$ cells and $\mathrm{B}$ cells. Immunophenotypic and functional studies have further revealed that $\mathrm{T}$ cells broadly comprise two subpopulations: helper/inducer $\left(\mathrm{CD}^{+}\right)$and suppressor/cytotoxic $\left(\mathrm{CD}^{+}\right)$. Recently, it has become clear that there exist at least two subpopulations of activated $\mathrm{CD}^{+} \mathrm{T}$ cells with 
differing cytokine synthesis profiles (Th1 and Th2). In broad terms, Th1 cells induce cell-mediated immunity, whilst Th2 cells induce humoral immunity. During development, $\mathrm{T}$ and $\mathrm{B}$ cells acquire antigen specificity but are only activated when specific antigen engages the appropriate receptor on the cell surface, i.e. the $\mathrm{T}$ cell receptor and the surface immunoglobulin respectively. T cells expressing CD4 almost invariably recognise foreign antigens/peptides in the context of self-MHC class II molecules, while $\mathrm{CD} 8 \mathrm{~T}$ cells recognise foreign antigen presented by self-MHC class I molecules (see review ${ }^{54}$ ). Presentation of antigen to $\mathrm{T}$ cells in the absence of appropriate co-stimulators, e.g. the molecule B7 on the APC interacting with CD28 on T cells, may result in clonal anergy. The cytokine milieu may play a role in $T$ cell activation and differentiation, for example in the selection of the Th1 or Th2 pathway, in that IFN $\gamma$ selects against Th2 and IL4 against Th1. ${ }^{55} \mathrm{~T}$ cells are highly dynamic and continually recirculate between blood, lymphoid and non-lymphoid tissues.

\section{Lymphocytes in the Normal Uveal Tract}

Originally it was believed $\mathrm{T}$ cells were not able to pass through the blood-brain and blood-ocular barrier and enter the parenchyma of the brain or retina; thus lymphocytes in the extravascular space were classically considered a feature of inflammation. However, there is now evidence that small numbers of lymphocytes do indeed penetrate these vascular barriers and actively migrate through the central nervous system parenchyma in non-diseased states. $^{56-58}$ The incidence of extravasated lymphocytes in these sites would be so low that they may rarely be encountered in histological sections. The extent of $\mathrm{T}$ cell trafficking in the uveal tract with its less developed vascular barriers (including a 'leaky' choriocapillaris) would be expected to be greater than in neural tissues; however, lymphocytes were originally reported to be absent or rare in the normal uveal tract of rodents ${ }^{9}$ and in human iris biopsies. ${ }^{59}$ Recent immunohistochemical staining of wholemounts has revealed the density of lymphocytes to range from 4 cells $/ \mathrm{mm}^{2}$ (pan T cell, $\mathrm{CD}^{+}$) in the rat iris to 20 cells $/ \mathrm{mm}^{2}$ in the normal rat choroid. ${ }^{12}$ Recent studies have revealed that some of these cells are $\mathrm{CD}^{+}$(Fig. 18), which may include NK cells although this remains to be clarified. Newly emerging evidence has shown that many cells and tissues in the intraocular environment (retina, cornea) are Fas ligand positive. When $\mathrm{Fas}^{+}$lymphocytes infiltrate the eye and come into contact with the ligand they undergo apoptosis in situ. ${ }^{60}$ This may act as a powerful mechanism regulating unwanted $\mathrm{T}$ cell infiltration in the intraocular environment.

To our knowledge there have been no specific published studies reporting the presence or absence of gamma/delta $\mathrm{T}$ cells in the uveal tract. This subset of $\mathrm{T}$ cells has a predilection for epithelial sites and has the ability to locally down-regulate unwanted immune responses. Immunohistochemical investigations in our laboratory have failed to identify any of these cells in the uveal tract.

B cells are usually absent from the normal eye of most species, although plasma cells are a conspicuous feature of the cellular infiltrate in EAU in guinea pigs, particularly in the late stages. ${ }^{61,62}$

\section{EOSINOPHILS}

Eosinophils, like neutrophils, are motile granulocytes. They are identifiable by virtue of the histochemical (acidophilic) and ultrastructural characteristics of their granules. Eosinophils remain in the blood for 6-12 hours before emigration into the extravascular connective tissues, where they remain for at least few days. ${ }^{63}$ There are believed to be around 200 times more eosinophils located in tissues than in the circulation. ${ }^{64}$ The characteristic eosinophilic granules contain four highly basic proteins: major basic protein (MBP) (granule core), eosinophil cationic protein (ECP), eosinophil-derived neurotoxin (EDN) and eosinophil peroxidase (EPO). These, together with superoxides and hydrogen peroxide, are believed to be the principal effector substances which kill parasites, bacteria and mycobacteria. Human eosinophils possess receptors for complement fragments and the Fc portion of IgG, $\mathrm{IgA}$, IgM and IgE. Upon cross-linkage of secretory IgA, eosinophils become less mobile and secrete ECP and EPO, which may explain their high numbers at mucosal surfaces where secretory $\operatorname{IgA}$ is found. Eosinophils also generate lipid mediators de novo, particularly leukotriene B4 and $\mathrm{C} 4$, lipoxins and platelet aggregating factor. ${ }^{65}$ They also release histaminase and aryl sulphatase which inactivate mast cell products such as histamine and slowreacting substance of anaphylaxis (SRS-A). This aids in dampening down inflammatory responses and reducing the degree of granulocyte migration to sites of inflammation. ${ }^{66}$

\section{Eosinophils.in the Uveal Tract}

To the author's knowledge there have been no studies specifically describing the distribution or presence of eosinophils in the normal uveal tract. In some species, e.g. guinea pigs, they constitute a large component of the choroidal infiltrate in EAU. ${ }^{62}$

In conclusion, the uveal tract of the eye, far from being a unique environment, is, like most vascular connective tissues, rich in a variety of immune cells which normally spend a portion of their life cycle outside the vasculature and lymphoid tissues. An understanding of the distribution, location and 
function of such cells in the normal eye and in inflammatory and immune-mediated diseases is crucial to unravelling the immunopathology of the various forms of uveitis and in planning strategies of intervention and immune modulation for diseases affecting the uvea.

The author wishes to thank research staff and students some of whose work is represented in this review, namely Julie Crewe, Sue Morrison, Tanya Butler and Raymond Steptoe.

Key words: Macrophage, Dendritic cell, Mast cell, Lymphocyte, Eosinophil, Iris, Ciliary body, Choroid.

\section{REFERENCES}

1. Adams DO. Macrophage activation. In: Roitt IM, Delves PJ, editors. Encyclopedia of immunology. New York: Academic Press, 1992:1020-6.

2. Unanue ER. Antigen-presenting function of the macrophage. Annu Rev Immunol 1984;2:395-428.

3. Unanue ER. Antigen presenting cells. In: Roitt IM, Delves PJ, editors. Encyclopedia of immunology. New York: Academic Press, 1992:114-5.

4. Duke-Elder S, Wybar KC. In: Duke-Elder S, editor. System of ophthalmology, vol. 2. London: Henry Kimpton, 1961:3.

5. Wobbman PR, Fine BS. The clump cells of Koganei: a light and electron microscope study. Am J Ophthalmol 1972;73:90-101.

6. McMenamin PG, Holthouse I, Holt PG. Class II MHC (Ia) antigen-bearing dendritic cells within the iris and ciliary body of the rat eye: distribution, phenotype, and relation to retinal microglia. Immunology 1992;77: 385-93.

7. McMenamin PG, Crewe JM, Morrison S, Holt PG. Immunomorphologic studies of macrophages and MHC Class II-positive dendritic cells in the iris and ciliary body of the rat, mouse and human eye. Invest Ophthalmol Vis Sci 1994;35:3234-50.

8. Allansmith MR, Baird RS, Bloch KJ. Macrophages in ocular tissues of rats: determination of their number after local anaphylaxis and other procedures. Arch Ophthalmol 1983;101:1930-4.

9. Williamson JSP, Bradley D, Streilein JW. Immunoregulatory properties of bone marrow-derived cells in the iris and ciliary body. Immunology 1989;67:96-102.

10. McMenamin PG, Crewe J. Endotoxin-induced uveitis: kinetics and phenotype of the inflammatory cell infiltrate and the response of the resident tissue macrophages and dendritic cells in the iris and ciliary body. Invest Ophthalmol Vis Sci 1995;36:1949-59.

11. Forrester JV, McMenamin PG, Holthouse I, Lumsden $\mathrm{L}$, Liversidge $\mathrm{J}$. Localisation and characterisation of major histocompatiblity complex class II-positive cells in the posterior segment of the eye: implications for induction of autoimmune uveoretinitis. Invest Ophthalmol Vis Sci 1994;35:64-77.

12. Butler TL, McMenamin PG. Resident and infiltrating immune cells in the uveal tract in the early and late stages of experimental autoimmune uveoretinitis. Invest Ophthalmol Vis Sci 1996;37:2195-210.

13. McMenamin PG. Immunocompetent cells in the anterior segment. Prog Ret Eye Res 1994;13:555-89.

14. Yoshida M, Yoshimura N, Hangai M, Tanihara $\mathrm{H}$, Honda $Y$. Interleukin- $1 \alpha$, interleukin- $1 \beta$, and tumor necrosis factor gene expression in endotoxin-induced uveitis. Invest Ophthalmol Vis Sci 1994;35:1107-13.
15. de Vos AF, Hoekzema R, Kijlstra A. Cytokines and uveitis: a review. Curr Eye Res 1992;11:581-97.

16. Kijlstra A. Lymphokine production: specific action on cells in uveitis. Eye 1997;11:200-5.

17. Steptoe RJ, Holt PG, McMenamin PG. Functional studies of major histocompatibility class II-positive dendritic cells and resident tissue macrophages isolated from the rat iris. Immunology 1995;85:630-7.

18. Steinman RM. The dendritic cell system and its role in immunogenicity. Annu Rev Immunol 1991;9:271-96.

19. Romani N, Schuler G, The immunologic properties of epidermal Langerhans cells as a part of the dendritic cell system. Springer Semin Immunopathol 1992;13: 265-79.

20. Girolomoni G, Simon JC, Bergstresser PR, Cruz PD. Freshly isolated spleen dendritic cells and epidermal Langerhans cells undergo similar phenotypic and functional changes during short term culture. J Immunol 1990;145:2820-6.

21. Fossum S. The life history of dendritic leukocytes (DL). Curr Top Pathol 1989;79:101-24.

22. Witmer-Pack MD, Olivier W, Valinsky J, Schuler G, Steinman RM. Granulocyte/macrophage colony-stimulating factor is essential for the viability and function of cultured murine epidermal Langerhans cells. J Exp Med 1987;166:1484-98.

23. Romani N, Koide S, Crowley M, Witmer PM, Livingstone AM, Fathman CG, et al. Presentation of exogenous protein antigens by dendritic cells to $T$ cell clones: intact protein is presented best by immature, epidermal Langerhans cells. J Exp Med 1989;169: 1169-78.

24. Janeway CA Jr, Bottomly K. Signals and signs for lymphocyte responses. Cell 1994;72:275-85.

25. Bakker M, Kijlstra A. The expression of HLA-antigens in the human anterior uvea. Curr Eye Res 1985;4: 599-604.

26. Abi-Hanna D, Wakefield D, Watkins S. HLA antigens in ocular tissue. I. In vivo expression in human eyes. Transplantation 1987;45:610-3.

27. Knisely TL, Anderson TM, Sherwood ME, Flotte TJ, Albert DM, Granstein RD. Morphologic and ultrastructural examination of $\mathrm{I}_{-} \mathrm{A}^{+}$cells in the murine iris. Invest Ophthalmol Vis Sci 1991;32:2423-31.

28. Steinman RM, Hoffman L, Pope M. Maturation and migration of cutaneous dendritic cells. J Invest Dermatol 1995;105:2S-7S.

29. Steptoe RJ, Holt PG, McMenamin PG. Origin and steady-state turnover of major histocompatibility complex class II-positive dendritic cells and resident-tissue macrophages in the iris of the rat eye. J Neuroimmunol 1996;68:67-76.

30. Holt PG, Haining S, Nelson DJ, Sedgwick JD. Origin and steady-state turnover of class II MHC-bearing dendritic cells in the epithelium of the conducting airways. J Immunol 1994;153:256-61.

31. Pugh CW, MacPherson GG, Steer HW. Characterisation of nonlymphoid cells derived from rat peripheral lymph. J Exp Med 1983;157:1758-79.

32. Niederkorn JY, Streilein JW. Induction of anterior chamber-associated immune deviation (ACAID) by allogeneic intraocular tumours does not require splenic metastases. J Immunol 1982;128:2470-4.

33. Egan RM, Yorkey C, Black R, Loh WK, Stevens JL, Woodward JG. Peptide-specific T clonal expansion in vivo following immunisation in the eye, an immuneprivileged site. J Immunol 1996;157:2262-71. 
34. Choudhury A, Al Palkanis V, Bowers WE. Characterisation and functional activity of dendritic cells from rat choroid. Exp Eye Res 1994;59:297-304.

35. Galli SJ. New approaches for the analysis of mast cell maturation, heterogeneity, and function. Fed Proc 1987;46:1906-14.

36. Gordon JR, Burd PR, Galli SJ. Mast cells as sources of multifunctional cytokines. Immunol Today 1990;11: 458-63.

37. Stead RH, Bienenstock J. Cellular interactions between the immune and peripheral nervous system: a normal role for the mast cells. In: Burger MM, Sordat $\mathrm{B}$, Zinkernagel, editors. Cell to cell interaction. Basel: Karger, 1990:170-87.

38. Godfrey WA. Characterisation of the choroidal mast cell. Trans Am Ophthalmol Soc 1987;85:557-99.

39. Smelser GK, Silver S. The distribution of mast cells in the normal eye: a method of study. Exp Eye Res 1963;2:134-40.

40. Levene RZ. Mast cells and amines in normal ocular tissues. Invest Ophthalmol Vis Sci 1962;1:531-43.

41. Louden C, Render JA, Carlton WW. Mast cell numbers in normal and glaucomatous canine eyes. Am J Vet Res 1990;51:818-9.

42. McMenamin PG, Krause WJ. Development of the eye in the North American opossum (Didelphis virginiana). J Anat 1993;183:343-58.

43. Vannas S. Mast cells in glaucomatous eyes. Acta Ophthalmol (Copenh) 1959;37:330-9.

44. Rodrigues MM, Hackett J, Donohoo P. Iris. In: Jakobiec FA, editor. Ocular anatomy, embryology, and teratology. Philadelphia: Harper and Row, 1982: 285-302.

45. Dieterich CE. Über die Ultrastruktur der Mastzellen in dem menschlichen Iris. Virchows Arch 1972;11:358-75.

46. Li Q, Fujino Y, Caspi RR, Najafian F, Nussenblatt RB, Chan C-C. Association between mast cells and the development of experimental autoimmune uveitis in different rat strains. Clin Immunol Immunopathol 1992;65:294-9.

47. Li Q, Whitcup SM, Fujino Y, Nussenblatt RB, Chan CC. The role of mast cells in endotoxin-induced uveitis. Invest Ophthalmol Vis Sci 1993;34:256-9.

48. Mochizuki M, Kuwabara T, Chan C-C, Nussenblatt RB, Metcalfe DM, Gery IG. An association between susceptibility to experimental autoimmune uveitis and choroidal mast cell numbers. J Immunol 1984;133: 699-701.

49. Dimlich RVM, Keller JT, Strauss TA, Fritts MJ. Linear arrays of homogeneous mast cells in the dura mater of the rat. J Neurocytol 1991;20:485-503.

50. Steptoe RJ, McMenamin PG, McMenamin CC. Distribution and characterisation of rat choroidal mast cells. Br J Ophthalmol 1994;78:211-8.
51. Galli SJ. Biology of disease. New insights into the 'riddle of the mast cells': microenvironmental regulation of mast cell development and phenotypic heterogeneity. Lab Invest 1990;62:5-33.

52. de Kozak Y, Saint-Laudy J, Benveniste J, Faure JP. Evidence for immediate hypersensitivity phenomena in experimental autoimmune uveoretinitis. Eur J Immunol 1981;11:612-7.

53. Steptoe RJ, McMenamin PG, McMenamin CC. Choroidal mast cell dynamics during experimental autoimmune uveitis in rat strains of differing susceptibility. Ocular Immunol Inflammation 1994;2:7-22.

54. Janeway CA Jr. The role of CD4 in T-cell activation: accessory molecule or co-receptor? Immunol Today 1989;10:234-8.

55. Romagnani S. Induction of Th1 and Th2 responses: a key role for the 'natural' immune response? Immunol Today 1992;13:379-81.

56. Hickey WF, Hsu BL, Kimura H. T-cell entry into the rat central nervous system. J Neurosci Res 1991;28: 254-60.

57. Hickey WF, Vass K, Lassmann H. Bone marrowderived elements in the central nervous system: an immunohistochemical and ultrastructural survey of rat chimeras. J Neuropathol Exp Neurol 1992;51:246-56.

58. Lassmann H, Schmied M, Vass K, Hickey WF. Bone marrow derived elements and resident microglia in brain inflammation. Glia 1993;7:19-24.

59. Wakefield D, McCluskey P, Palladinetti P. Distribution of lymphocytes and cell adhesion molecules in iris biopsy specimens from patients with uveitis. Arch Ophthalmol 1992;110:121-5.

60. Griffith TS, Brunner T, Fletcher SM, Green DR, Ferguson TA. Fas ligand-induced apoptosis as a mechanism of immune privilege. Science 1995;270: 1189-92.

61. Forrester JV, Borthwick GM, McMenamin PG. Ultrastructural pathology of S-antigen uveoretinitis. Invest Ophthalmol Vis Sci 1985;26:1281-92.

62. Harper FH, Liversidge J, Thompson AW, Forrester JV. Interphotoreceptor binding protein induced experimental autoimmune uveitis: an immunophenotypic analysis using alkaline phosphatase anti-alkaline phosphatase staining, dual immunofluorescence and confocal microscopy. Curr Eye Res 1992; (Suppl) 11: 129--34

63. Spry CJF, Kay AB, Gleich GJ. Eosinophils. Immunol Today 1992;10:384-7.

64. Spry CJF. Mechanism of eosinophilia. VI. Eosinophil mobilisation. Cell Tissue Kinet 1971;4:365-74.

65. Rothenberg ME, Owen WF, Stevens RL. Mast cells and eosinophils. Int Ophthalmol Clin 1988;28:267-74.

66. Silberstein DS. Eosinophils. In: Roitt IM, Delves PJ, editors. Encyclopedia of immunology. New York: Academic Press, 1992:512-4. 